\title{
RETENÇÃO PELA PALHADA, DE HERBICIDAS APLICADOS EM PRÉ- EMERGÊNCIA NACULTURA DA SOJA, EM PLANTIO DIRETO
}

\author{
Benedito N. Rodrigues ${ }^{1}$, João de Lima ${ }^{1}$ e Inês F. U. Yada ${ }^{1}$
}

'IAPAR. Caixa Postal 481. Londrina, PR 86001-970

\section{RESUMO}

\begin{abstract}
O objetivo deste trabalho foi avaliar a retenção pela palhada, das misturas imazaquin+pendimethalin e sulfentrazone+metribuzin, aplicadas em pré-emergência, no sistema de plantio direto de soja. Os experimentos foram conduzidos na sede do IAPAR em Londrina-PR, na safra 1998/99, utilizando-se palha de aveia-preta (Avena strigosa) como cobertura morta. O delineamento dos experimentos (em número de dois), foi o de blocos ao acaso com cinco repetições. Os tratamentos foram constituídos pelas doses de herbicidas: zero; $0,5 \mathrm{~N} ; \mathrm{N} ; 1,5 \mathrm{~N}$ e $2 \mathrm{~N}$, sendo $\mathrm{N}$ a dose normal recomendada para a cultura (no caso, $150 \mathrm{~g} /$ ha de imazaquin $+1200 \mathrm{~g} / \mathrm{ha}$ de pendimethalin e $350 \mathrm{~g} / \mathrm{ha}$ de sulfentrazone $+360 \mathrm{~g} / \mathrm{ha}$ de metribuzin). Utilizou-se a cultivar de soja FT-2000. Os herbicidas foram aplicados com pulverizador de precisão propelido a $\mathrm{CO}_{2}$, munido com barra de seis bicos Teejet Flat Spray em leque, 80.02, distanciados $50 \mathrm{~cm}$ entre sí, vazão de $2001 /$ ha. Vinte e quatro horas após a aplicação dos herbicidas, os experimentos receberam 48,3 mm de lâmina de água. No dia seguinte, foram amostrados palha e solo em todas as parcelas para análise cromatográfica de resíduos. Os resultados mostraram que a lâmina de água promoveu a lixiviação de praticamente todo o imazaquin da palha para o solo, o que não ocorreu com o pendimethalin, que ficou todo retido na palha. O sulfentrazone também foi lixiviado para o solo, sendo que $50 \%$ do metribuzin aplicado foi detectado no solo após a chuva.
\end{abstract}

Palavras chave: cromatografia, plantas daninhas, resíduos.

\section{ABSTRACT \\ Herbicide retention by mulching in soybean, under no-tillage system}

The objective of this trial was to study the mulch retention of the herbicide mixtures imazaquin + pendimethalin and sulfentrazone + metribuzin applied in pre-emergence for soybean under no-tillage system. The experiment was settled in Londrina-PR, Brazil, with black oat (Avena strigosa) mulch. A randomized complete block design was used. The treatments comprised the following rates of herbicides: zero, $0.5 \mathrm{~N}, 1.0 \mathrm{~N}, 1.5 \mathrm{~N}$ and $2.0 \mathrm{~N}$ ( $\mathrm{N}=$ normal rate of the herbicide). In the present study, $\mathrm{N}=150 \mathrm{~g} / \mathrm{ha}$ imazaquin $+1200 \mathrm{~g} / \mathrm{ha}$ pendimethalin and $350 \mathrm{~g} / \mathrm{ha}$ sulfentrazone $+360 \mathrm{~g} / \mathrm{ha}$ metribuzin. After twenty four hours of herbicide applications, $48.3 \mathrm{~mm}$ of water was applied in the experiments. In the next day, samples of soil and straw were taken for chromatographic analysis purposes. The results showed that $100 \%$ of imazaquin and sulfentrazone leached from the straw to the soil. Approximately $50 \%$ of metribuzin and $100 \%$ of pendimethalin were retained by the oat straw.

Key words: chromatography, weeds, residues.

\section{INTRODUÇÃO}

O sistema de plantio direto na palha é um dos mais importantes meios de controle de erosão e de plantas daninhas do Sul do Brasil. As recomendações de herbicidas, tan- to de aplicação em pré como em pós-emergência, têm sido as mesmas, tanto para o sistema de plantio direto como convencional, independente da quantidade de palha existente sobre o terreno. 
Em trabalhos anteriores, foi verificado que alguns herbicidas são retidos na palha, mesmo ocorrendo chuvas logo após a aplicação, como é o caso do metribuzin (Banks e Robinson, 1982), oryzalin (Banks e Robinson, 1984), das acetanilidas alachlor, acetochlor e metolachlor (Banks e Robinson, 1986), trifluralin (Rodrigues et al. 1998). Outros são facilmente lixiviados para o solo, com chuvas que ocorram 24 horas após a aplicação, como é o caso de atrazine (Rodrigues e Almeida, 1986; Fornarolli, 1997). Esses resultados, no entanto, foram obtidos com os produtos aplicados isoladamente, nunca em misturas.

O objetivo do presente trabalho é estudar a retenção pela palhada de algumas misturas de herbicidas, aplicados em pré-emergência na cultura da soja, no sistema de plantio direto na palha.

\section{MATERIAL E MÉTODOS}

No estágio de grão leitoso, em 17/09/98, foi aplicado glyphosate em toda área dos experimentos (1,7 1/ha de Trop - 360 g/1) para promover a dessecação da aveia preta. Previamente à semeadura da soja foi passado um rolo, sem facas, para uniformizar a cobertura morta.

Os herbicidas de pré-emergencia foram aplicados imediatamente após a semeadura da soja, cultivar FT-2000, em 14/10/98, com pulverizador de precisão propelido a $\mathrm{CO}_{2}$, munido de barra com 6 bicos Teejet Flat Spray em leque, 80.02 , distanciados $50 \mathrm{~cm}$ entre si, com $3 \mathrm{~m}$ de alcance (largura da parcela) e vazão de 200 l/ha de calda.

Paralelamente à aplicação, em área fora dos experimentos, em amostras ao acaso com $1 \mathrm{~m}^{2}$, foi determinado o peso da matéria seca da palha no momento da aplicação, obtendo-se $3700 \mathrm{~kg} / \mathrm{ha}$ de matéria seca. Para isso, a palha foi acondicionada em sacos de papel e colocada em estufa até peso constante.

O trabalho foi constituído de dois experimentos, sendo um conduzido com a mistura imazaquin+pendimethalin e o outro com a mistura sulfentrazone + metribuzin. Ambos experimentos foram delineados em blocos ao acaso com 5 tratamentos em cinco repetições. Os tratamentos foram constituídos pelas seguintes doses de herbicidas: zero, 0,5 N, N, $1,5 \mathrm{~N}$ e $2 \mathrm{~N}$, onde $\mathrm{N}=$ dose normal recomendada pelo fabricante, conforme Rodrigues e Almeida (1998). No primeiro experimento, as doses normais foram: imazaquin (150 g/ha) + pendimethalin (1200 g/ha) (5,0 litros/ha de Squadron $30+240 \mathrm{~g} / 1)$. No segundo experimento, as doses normais foram: sulfentrazone ( $350 \mathrm{~g} / \mathrm{ha})(0,7$ litros/ha de Boral $500 \mathrm{~g} / \mathrm{l})$ + metribuzin (360 g/ha) (0,75 litros/ha de Sencor $480 \mathrm{~g} / 1)$. As parcelas apresentaram as dimensões de $3 \mathrm{~m} \times 6 \mathrm{~m}$ (18 $\mathrm{m}^{2}$ ), sendo deixadas, nas laterais, faixas sem palha, não tratadas, que foram utilizadas como termo de comparação nas avaliações visuais de controle.
Vinte e quatro horas após a aplicação dos herbicidas, todo o experimento foi irrigado por aspersão, aplicando-se $20 \mathrm{~mm}$ de água, com a finalidade de forçar a lixiviação dos herbicidas da palha para o solo. Logo após a irrigação ocorreu uma precipitação natural de $28,3 \mathrm{~mm}$, perfazendo portanto, um total de lâmina de água de $48,3 \mathrm{~mm}$. No dia seguinte à chuva, foram amostrados solo e palha de todas as parcelas, com amostrador de $10 \times 10 \mathrm{~cm}$ com $10 \mathrm{~cm}$ de profundidade. As amostras foram levadas ao Laboratório de Ecofisiologia do IAPAR para análise cromatográfica de resíduos, com metodologia específica desenvolvida para esta finalidade.

No experimento de campo foram feitas avaliações visuais em percentagem de controle e fitotoxicidade (0-100\%) aos 30 e 50 dias após a semeadura (D.A.S.). Foi também determinada a produção de grãos de soja em $\mathrm{kg} / \mathrm{ha}$ a $14 \%$ de umidade. Todos os dados foram submetidos à análise de regressão.

\section{RESULTADOS E DISCUSSÃO}

\section{a) imazaquin + pendimethalin}

A mistura imazaquin + pendimethalin provocou leve fitotoxicidade na soja, principalmente com a meia-dose e com a dose normal. Quando se utilizaram as doses maiores, os sintomas tornaram-se mais acentuados, caracterizados por redução de altura e leve clorose. Os valores correspondentes às percentagens de injúria na soja, com avaliações feitas aos 30 e 50 dias após a semeadura (DAS), podem ser observados na Figura 1. Como conseqüência de maior injúria, a dose dobrada provocou redução na produção (Figura 2).

O controle da Brachiaria plantaginea cresceu com o aumento da dose dos herbicidas, chegando a um nível máximo de $80 \%$ na dose maior aos 30 DAS. Nesta avaliação, havia 88 plantas/metro quadrado nas faixas laterais, utilizadas com termo de comparação. Na dose normal não passou dos $70 \%$ de controle. Nas parcelas sem herbicidas, o controle foi de $40 \%$ aos 30 DAS e $20 \%$ aos 50 DAS (Figura 3).

O controle de Euphorbia heterophylla e de Bidens pilosa foi realizado de maneira semelhante (Figuras 4 e 5). Os maiores valores (entre 90 e $100 \%$ ), foram obtidos com as maiores doses, na avaliação realizada aos 30 DAS. Nessa época, havia 32 plantas/metro quadrado de $E$. heterophylla e 9 plantas/metro quadrado de B. pilosa nas faixas comparativas. Aos 50 DAS, a tendência de controle manteve-se a mesma, evidentemente com valores inferiores aos observados na avaliação anterior.

As análises cromatográficas de resíduos, mostraram que o teor de imazaquin detectado no solo era de aproxima- 


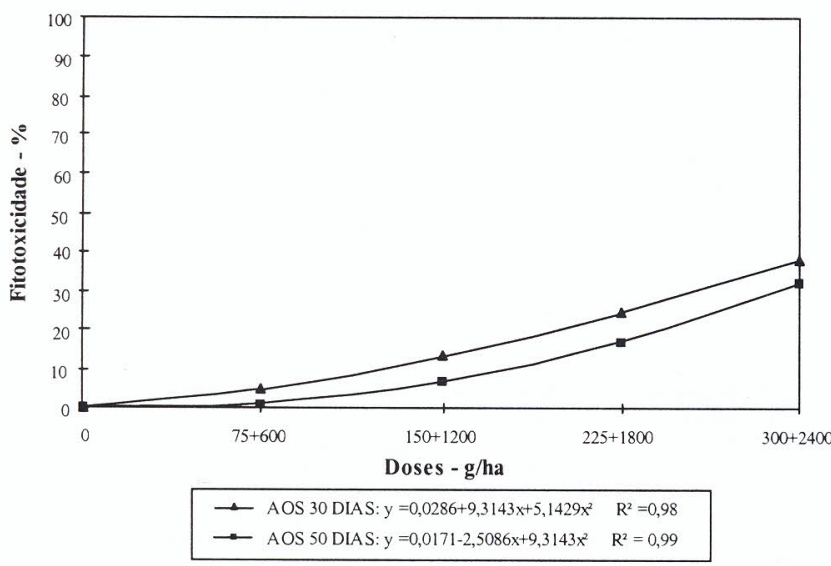

Figura 1 . Fitotoxicidade aos 30 e 50 dias após a semeadura da soja, causada pela mistura de imazaquin + pendimethalin.

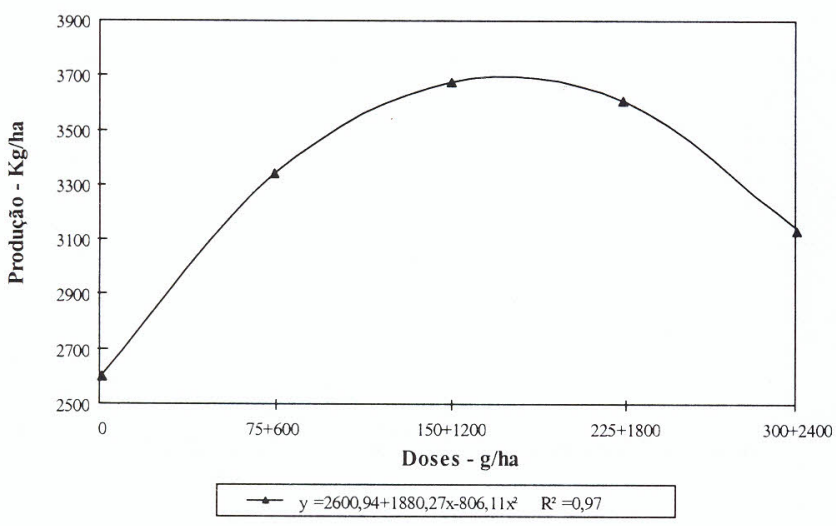

Figura 2. Produção de grãos de soja conforme as doses da mistura de imazaquin + pendimethalin.

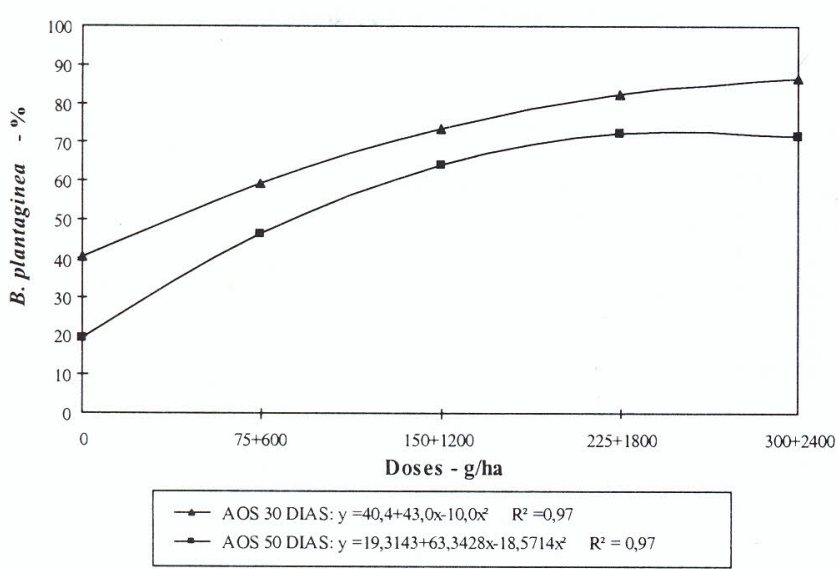

Figura 3. Percentagem de controle de B. plantaginea aos 30 e 50 dias após a semeadura da soja, obtida pela mistura de imazaquin + pendimethalin.

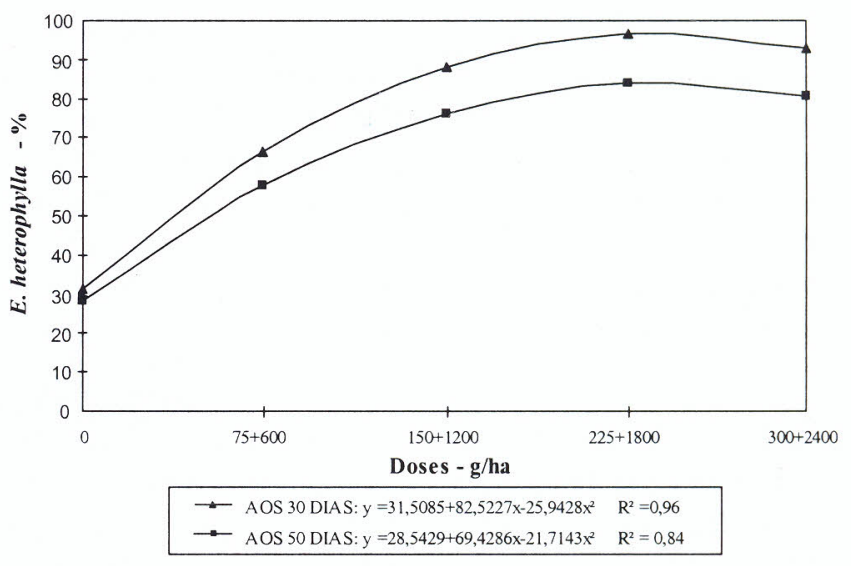

Figura 4. Percentagem de controle de E. heterophylla aos 30 e 50 dias após a semeadura da soja, obtida pela mistura de imazaquin + pendimethalin.

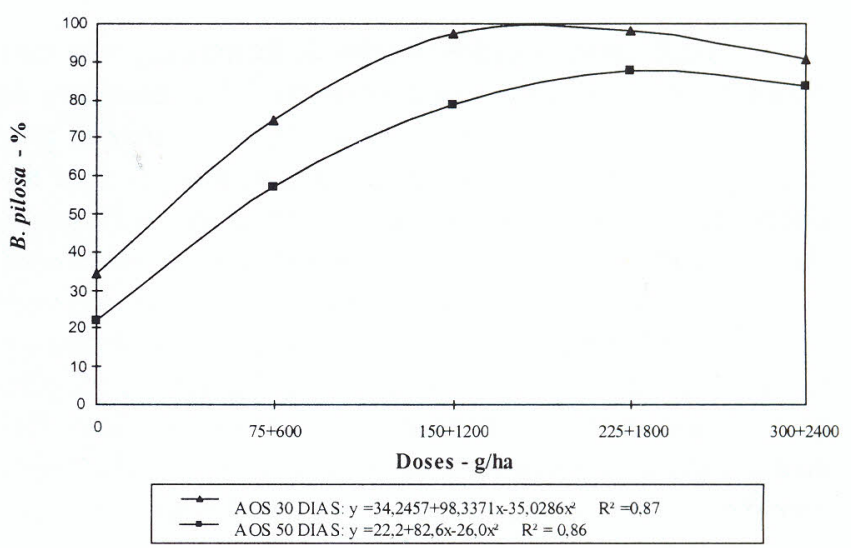

Figura 5. Percentagem de controle de B. pilosa aos 30 e 50 dias após a semeadura da soja,

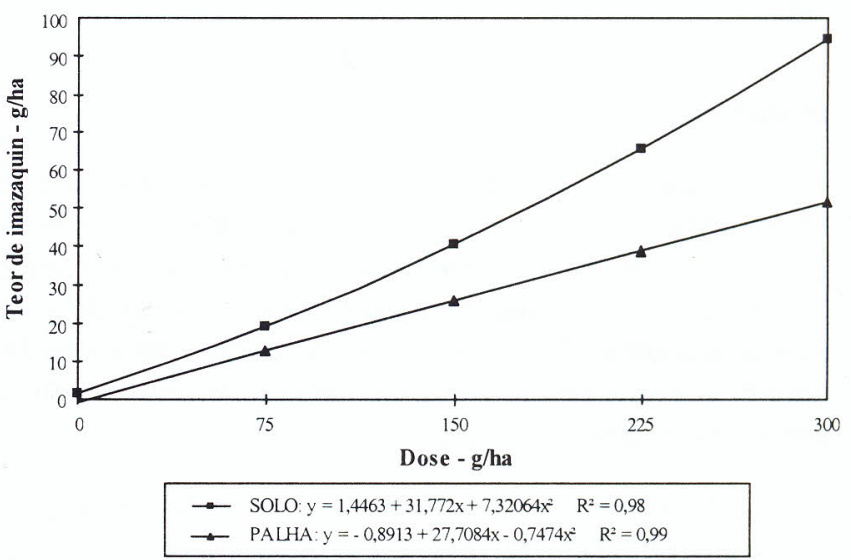

Figura 6. Teor de imazaquin no solo e na palha em função da dose deste produto após uma chuva de $48,3 \mathrm{~mm}$, ocorrida 24 horas depois da aplicação da mistura de imazaquin + pendimethalin. 
damente $27 \%$ do total do produto aplicado na dose normal, percentual este que se manteve também com as doses maiores (Figura 6). Como o percentual detectado na palha também foi baixo, não passando dos $18 \%$ nas doses utilizadas, perfazendo um total de $45 \%$ entre palha + solo, observa-se que $55 \%$ do imazaquin aplicado não foi recuperado por cromatografia, podendo ter sido lixiviado para as camadas mais profundas do solo devido à lâmina de água aplicada.

Ao contrário do imazaquin, praticamente todo o pendimethalin aplicado ficou retido na palha, mesmo com a lâmina de água de 48,3 mm. Apenas traços desse herbicida foram detectados no solo (Figura 7). O comportamento desta dinitroanilina foi completamente diferente do trifluralin, conforme estudos realizados por Rodrigues et al. (1998). Naquela oportunidade, esses autores verificaram que apenas traços de trifluralin foram detectados na palha e no solo, tanto antes como após a irrigação de $20 \mathrm{~mm}$ ocorrida 24 horas após a aplicação do herbicida.

Analisando os dados obtidos de forma conjunta, verificamos que o controle das plantas daninhas presentes no experimento foi realizado, possivelmente, apenas pelo imazaquin, uma vez que o pendimethalin praticamente não chegou ao solo. Outro aspecto importante é que, pela quantidade de palha existente sobre o terreno (no presente caso, $3700 \mathrm{~kg} /$ ha de matéria seca), o uso do herbicida não pode ser dispensado, uma vez que o controle das ervas obtido nos tratamentos sem herbicidas não passou dos $40 \%$ nas avaliações visuais realizadas. Portanto, somando-se os efeitos físico e alelopático da cobertura morta da aveia (Almeida, 1988), com o efeito dos herbicidas, mesmo que estes tenham ficado em grande parte retidos na palha (caso do pendimethalin) ou perdidos possivelmente por lixiviação (caso do imazaquin), obteve-se o controle das plantas daninhas presentes. No caso da $B$. plantaginea, provavelmente o controle teria sido melhor se o pendimethalin não ficasse tão fortemente retido à palha.

\section{b) sulfentrazone + metribuzin}

A mistura sulfentrazone + metribuzin provocou leve fitotoxicidade na soja, provocada principalmente por redução no crescimento. Os valores correspondentes às porcentagens de injúria na soja, com avaliações feitas aos 30 e 50 dias após a semeadura (DAS), podem ser observados na Figura 8. A produção de grãos, no entanto, aumentou com o aumento das doses da mistura (Figura 9).

O controle da B. plantaginea, E. heterophylla e B. pilosa, as três espécies presentes neste experimento, nas mesmas densidades populacionais citadas no experimento anterior, aumentou com o aumento da dose dos componentes da mistura (Figuras 10, 11, e 12), sendo que, à dose normal, as espécies dicotiledôneas não foram controladas satisfatoriamente, havendo necessidade de doses maiores.

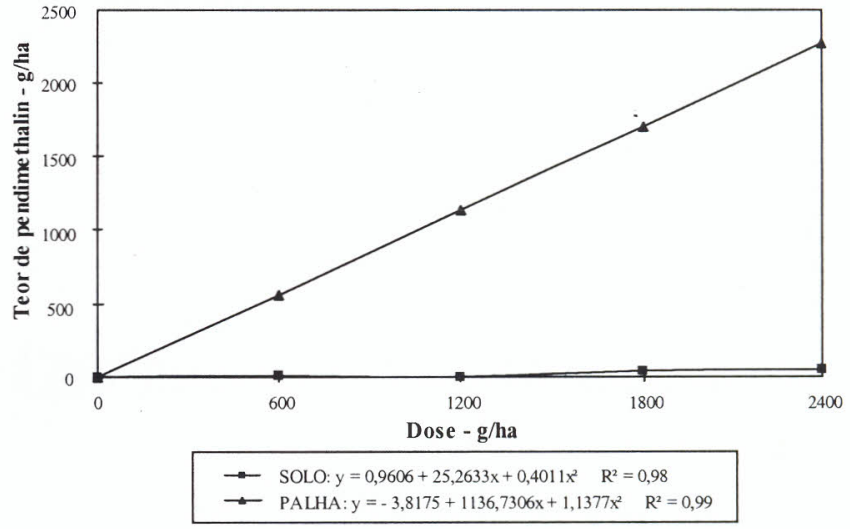

Figura 7. Teor de pendimethalin no solo e na palha em função da dose deste produto após uma chuva de $48,3 \mathrm{~mm}$, ocorrida 24 horas depois da aplicação da mistura de imazaquin + pendimethalin.

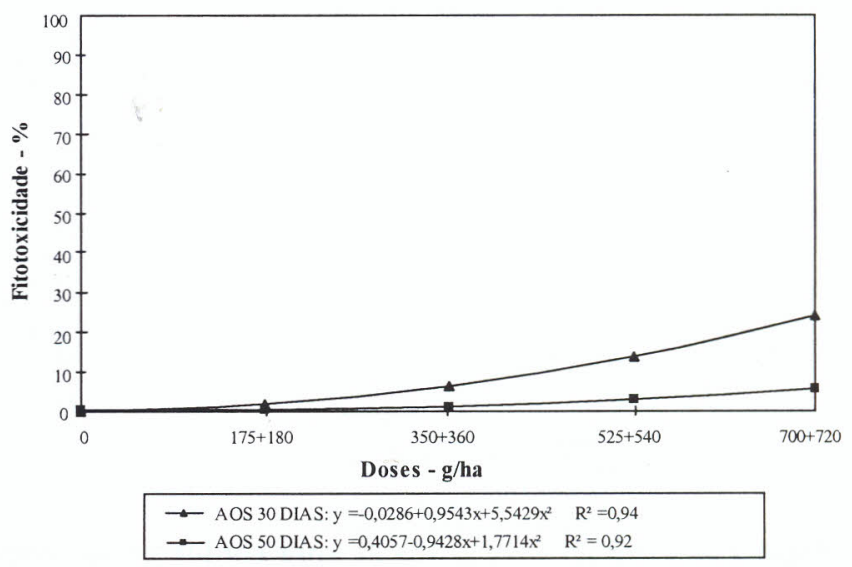

Figura 8.Fitotoxicidade aos 30 e 50 dias após a semeadura da soja, causada pela mistura de sulfentrazone + metribuzin.

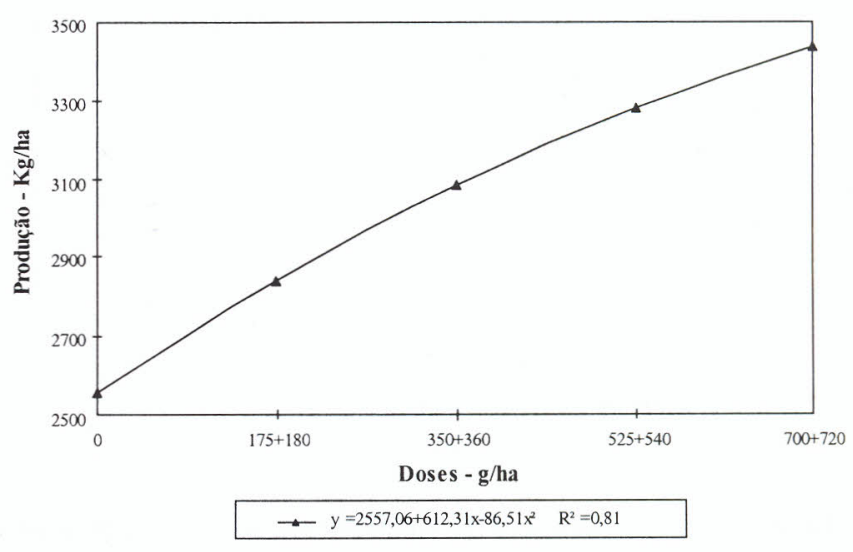

Figura 9. Produção de grãos de soja conforme as doses da mistura de sulfentrazone + metribuzin. 


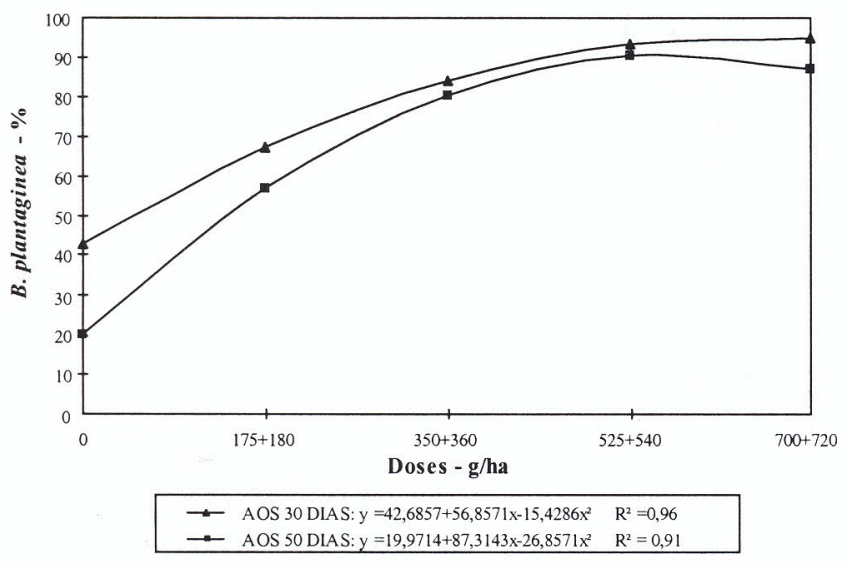

Figura 10. Percentagem de controle de B. plantaginea aos 30 e $\mathbf{5 0}$ dias após a semeadura da soja, obtida pela mistura de sulfentrazone + metribuzin.

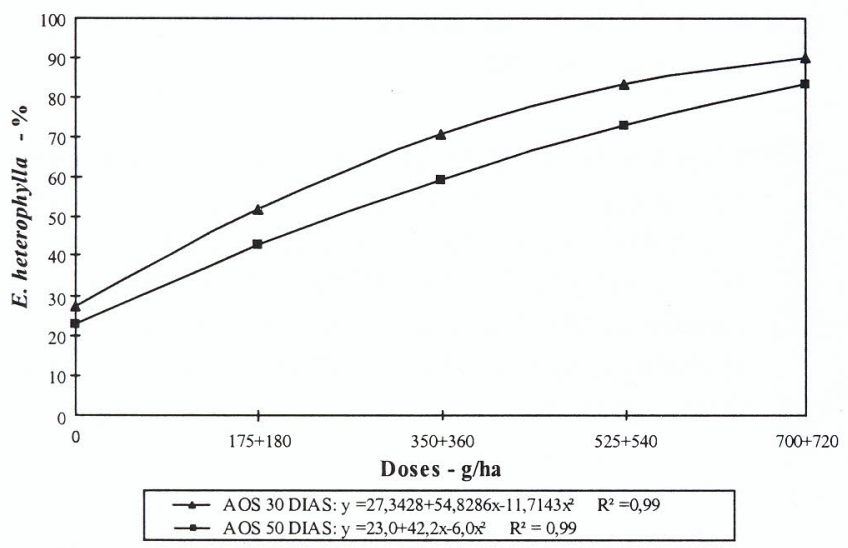

Figura 11. Percentagem de controle de E. heterophylla aos 30 e 50 dias após a semeadura da soja, obtida pela mistura de sulfentrazone + metribuzin.

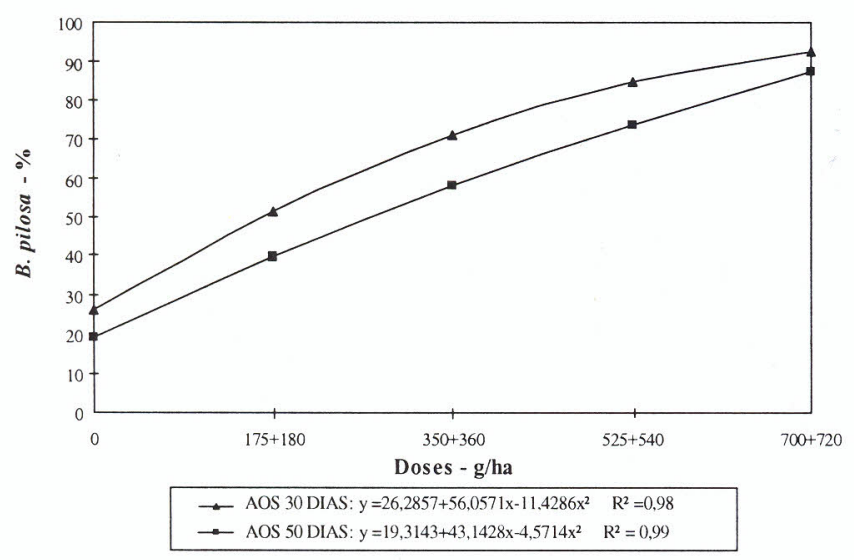

Figura 12. Percentagem de controle de $B$. pilos $a$ aos $30 \mathrm{e}$ 50 dias após a semeadura da soja, obtida pela mistura de sulfentrazone + metribuzin.

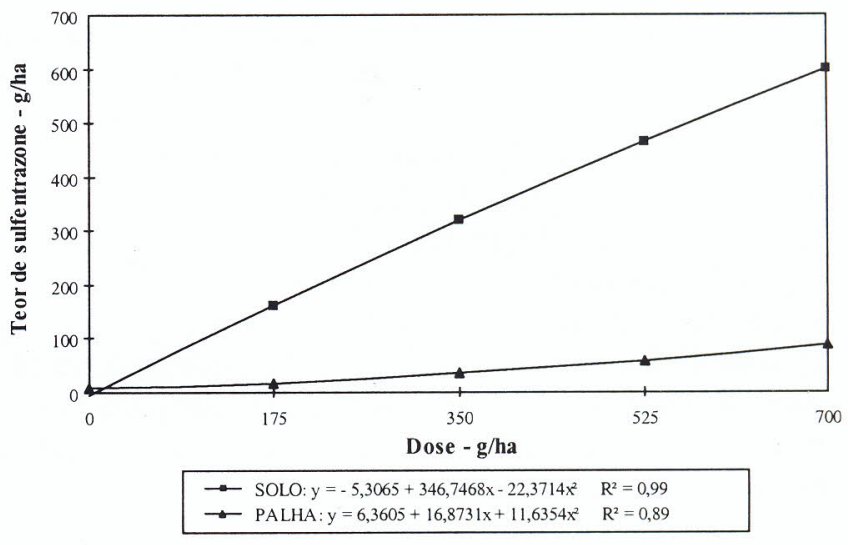

Figura 13. Teor de sulfentrazone no solo e na palha em função da dose deste produto após uma chuva de $48,3 \mathrm{~mm}$, ocorrida 24 horas depois da aplicação da mistura de sulfentrazone + metribuzin.

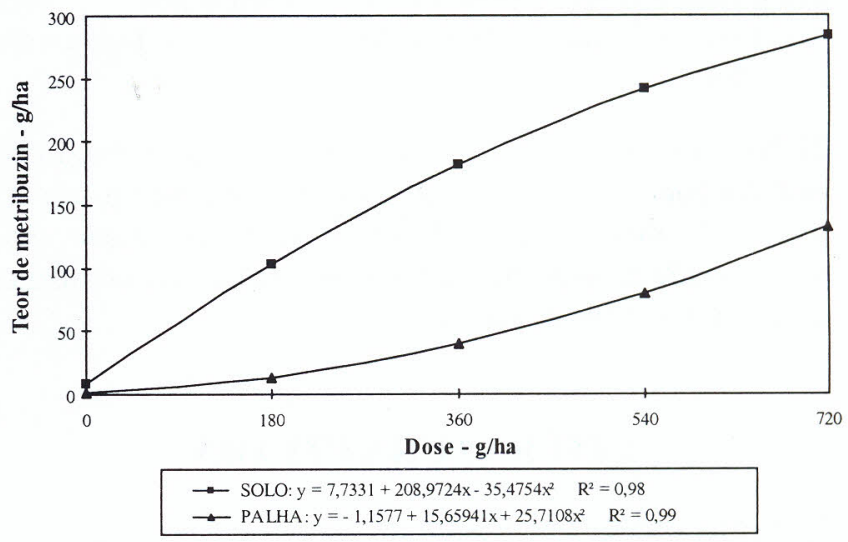

Figura 14. Teor de metribuzin no solo e na palha em função da dose deste produto após uma chuva de $48,3 \mathrm{~mm}$, ocorrida 24 horas depois da aplicação da mistura de sulfentrazone + metribuzin.

Somando-se os teores de sulfentrazone obtidos na palha e no solo através das análises cromatográficas de resíduos (Figura 13), podemos observar que, em praticamente todas as doses, a soma é aproximadamente igual à quantidade originalmente aplicada (mais de $80 \%$ chegou ao solo), o que nos leva a crer que não houve perda de produto. Esses dados são bem diferentes daqueles obtidos por Rodrigues et al. (1998) com sulfentrazone aplicado isoladamente. Naquele trabalho, os autores verificaram que, apesar da chuva ser menor (apenas $20 \mathrm{~mm}$ ), praticamente $50 \%$ do sulfentrazone foi lixiviado para as camadas mais profundas do solo (mais de 10 $\mathrm{cm}$ de profundidade). Provavelmente, neste caso, a presença do metribuzin na mistura tenha influído na menor lixiviação do sulfentrazone. 
Os dados obtidos com metribuzin, são coincidentes com os obtidos nos Estados Unidos por Banks e Robinson (1982). Naquele trabalho, os autores verificaram que menos de $45 \%$ do metribuzin aplicado isoladamente foi detectado no solo, após uma chuva de 12,5 mm ocorrida imediatamente após a aplicação do produto sobre $2250 \mathrm{~kg} / \mathrm{ha}$ de palha de trigo. No presente trabalho, aproximadamente 40 a $50 \%$ do metribuzin aplicado foi detectado no solo após a lâmina de água de $48,3 \mathrm{~mm}$, ficando de 10 a $15 \%$ retido na palha (Figura 14). Os outros 35 a $50 \%$ do total aplicado podem ter-se perdido ou por lixiviação para camadas inferiores do solo ou por decomposição na própria palha.

\section{CONCLUSÕES}

1) $\mathrm{Na}$ mistura imazaquin + pendimethalin, a ocorrência de uma lâmina de água de 48,3 mm, 24 horas após a aplicação, promove a lixiviação de praticamente todo o imazaquin da palha para o solo; o contrário ocorre com o pendimethalin que, mesmo nessas condições, fica praticamente todo retido na palha.

2) No caso da mistura sulfentrazone + metribuzin, o sulfentrazone é totalmente lixiviado da palha para o solo. $\mathrm{O}$ metribuzin pode sofrer lixiviação acentuada; no entanto, apenas a metade do total aplicado é detectada no solo na camada de 0 a $10 \mathrm{~cm}$ de profundidade.

\section{LITERATURA CITADA}

ALMEIDA, F. S. A alelopatia e as plantas. Londrina: IAPAR, 1988. 60 p. (Circular IAPAR, 53).
BANKS, P. A; ROBINSON, E. L. The influence of straw mulch on the soil reception and persistence of metribuzin. Weed Science, Champaign, v.30, n.2, p.164-8. 1982.

BANKS, P. A; ROBINSON, E. L. The fate of oryzalin applied to straw-mulched and non-mulched soils. Weed Science, Champaign, v.32, p.269-272, 1984.

BANKS, P. A; ROBINSON, E. L. Soil reception and activity of acetochlor, alachlor and metolachlor as affected by wheat (Triticum aestivum), atraw irrigation. Weed Science, Champaign, v.34, p.607-611, 1986.

FORNAROLLI, D. A. Influência da cobertura morta no comportamento do herbicida atrazine. UEL-Londrina, PR, 1997. Dissertação de Mestrado.

RODRIGUES, B. N; ALMEIDA, F. S. Guia de Herbicidas. 4ed. Londrina, PR: Ed. dos Autores, 1998. 648p.

RODRIGUES, B. N; ALMEIDA, F. S. Influência da cobertura morta no comportamento dos herbicidas atrazine e metolachlor no sistema de plantio direto. In: FUNDAÇÃO INSTITUTO AGRONÔMICO DO PARANÁ, Londrina, PR. Resultados de pesquisa da Área de Herbologia, safras 1984/85 e 1985/86. Londrina, 1986. (Mimeografado).

RODRIGUES, B. N.; LIMA, J.; YADA, I. F. U.; FORNAROLLI, D. A. Influência da cobertura morta no comportamento do herbicida trifluralin. Planta Daninha, v.16, n.2, p. 163-173, 1998. 